\title{
The "Alzheimer's disease signature": potential perspectives for novel biomarkers
}

\author{
Sergio Davinelli ${ }^{1}$, Mariano Intrieri ${ }^{1}$, Claudio Russo ${ }^{1}$, Alfonso Di Costanzo ${ }^{1}$, Davide Zella ${ }^{2}$, Paolo Bosco ${ }^{3}$ and \\ Giovanni Scapagnini ${ }^{*}$
}

\begin{abstract}
Alzheimer's disease is a progressive and neurodegenerative disorder which involves multiple molecular mechanisms. Intense research during the last years has accumulated a large body of data and the search for sensitive and specific biomarkers has undergone a rapid evolution. However, the diagnosis remains problematic and the current tests do not accurately detect the process leading to neurodegeneration. Biomarkers discovery and validation are considered the key aspects to support clinical diagnosis and provide discriminatory power between different stages of the disorder. A considerable challenge is to integrate different types of data from new potent approach to reach a common interpretation and replicate the findings across studies and populations. Furthermore, long-term clinical follow-up and combined analysis of several biomarkers are among the most promising perspectives to diagnose and manage the disease. The present review will focus on the recent published data providing an updated overview of the main achievements in the genetic and biochemical research of the Alzheimer's disease. We also discuss the latest and most significant results that will help to define a specific disease signature whose validity might be clinically relevant for future AD diagnosis.
\end{abstract}

\section{Background}

Alzheimer's disease (AD) is the most common form of dementia and age-dependent neurodegenerative disorder. It represents one of the major public health problems in our modern age and epidemiological investigations estimated that the amount of people with $\mathrm{AD}$ will rise to over 100 million by 2050 [1]. The main hallmarks of the disease are decreased number of neurons, formation of amyloid plaques and generation of neurofibrillary tangles which results in neuronal dysfunction. Although a definitive diagnosis of AD is not possible until autopsy, diagnostic tools to detect $\mathrm{AD}$ have improved considerably in recent years. Even though there was significant technological advance, improved antemortem AD diagnostic methods are still needed. To date, early diagnosis of AD is difficult, therefore an important challenge for the successful management of $\mathrm{AD}$ is the development of new tools to detect $\mathrm{AD}$ in its earliest stages which could predict the progression of the disease. In addition, it is necessary to translate neurobiological knowledge and biomarker research into clinical

\footnotetext{
* Correspondence: g.scapagnini@gmail.com

'Department of Health Sciences, University of Molise, Campobasso, Italy Full list of author information is available at the end of the article
}

practice. In this perspective, there is a significant effort to discover novel candidate biomarkers that together with those well established will be able to improve the accuracy of diagnosis. Fortunately, there has been a significant progress toward the use of potent and modern methods which allow the concomitant measurement of several biomarkers but we are far to define and create a reliable diagnostic and prognostic profile.

According to the National Institute of Health, a biomarker is "a characteristic that is objectively measured and evaluated as an indicator of normal biologic processes, pathogenic processes, or pharmacologic responses to a therapeutic intervention" [2].

Nowadays there is still not an ideal biomarker able to improve differential diagnosis, track disease progression and measure treatment efficacy. This means that we have an urgent need to develop biomarkers that are sensitive and specific to AD pathology with positive and negative predictive value for the disorder [3]. In addition, it is crucial to understand the complex relationship between the different biomarkers. The main tests for biomarkers classes used in the diagnosis and prognosis of AD are positron emission tomography (PET) neuroimaging of $\beta$-amyloid $(A \beta)$ protein deposition, magnetic resonance imaging

\section{Biomed Central}


(MRI) of volume hippocampus and other brain structures, quantification of abundance of proteins in cerebrospinal fluid (CSF) and blood (i.e., plasma and serum) especially with quantitative proteomics strategies, genotyping of genetic polymorphism and finally emerging approaches such as high throughput techniques, trascriptome analysis and next-generation DNA sequencing method.

Here, we will discuss the recent literature on the role of biological markers in $\mathrm{AD}$, summarizing the status in this field and focusing on the most promising genetic and biochemical biomarkers.

\section{Pathogenesis of Alzheimer's Disease and Amyloid Hypothesis}

$\mathrm{AD}$ is the most frequent cause of dementia affecting more than 53 million people [4] worldwide and is often a multifactorial disease. The key clinical features of $\mathrm{AD}$ are progressive memory loss and cognitive decline. The disorder is histopathologically and morphologically characterized by deposition of extracellular plaques (A $\beta 42)$ and intracellular neurofibrillary tangles (tau) that are believed to play an active role in the neurodegenerative process of $\mathrm{AD}$ [5]. The amyloid cascade hypothesis articulated by J. Hardy is the central paradigm for the cause of $\mathrm{AD}$ and was prominent in the field of AD research [6]. The core of this hypothesis is an imbalance between the production and the clearance of $A \beta$ in the brain [7]. The proteolytically derived product of amyloid precursor protein (APP) A $\beta 42$ is the main constituent of the amyloid plaques. $A \beta$ is generated by sequential actions of $\beta$-secretase and $\gamma$-secretase on APP through an amyloidogenic pathway and there are several truncated $A \beta$ isoforms in the brain. The enzyme accountable for the $\beta$-secretase activity is $\beta$-site APP-cleaving enzyme 1 (BACE1) and an increased activity have been found in cases of prodromal AD $[8,9]$. Detailed description of the main causes of the AD have been extensively reviewed elsewhere [10] but it is essential to point out that the amyloid cascade hypothesis has less support today. Recently, many patients with severe AD showed no plaques at the post-mortem analysis and conversely the plaques may be found in the elderly without dementia [11]. It has now proposed that other forms of $A \beta$ such as soluble $A \beta$ oligomers cause AD [12] and interestingly it has been reported that the composition and levels of postmortem CSF biomarkers can differ from that of antemortem $[13,14]$. Another neuropathological hallmark of AD are inclusions of microtubule-associated protein tau that is the major constituent of neurofibrillary tangles. The abnormal hyperphosphorylation of tau causes dysfunctions in the axonal transport mainly due to the generation of insoluble aggregates during the formation of neurofibrillary tangles. Tau undergoes to post-traslational modifications [15] that may be involved in the pathology of the disease. In particular, it can be phosphorylated on multiple sites (to date 39 different sites verified) [16], which seems to be important in reducing the affinity of tau for microtubules [17]. As proposed by the amyloid hypothesis, changes in tau and resultant neurofibrillary tangles formation are triggered by toxic concentrations of $A \beta$. Despite the fact that the link between $A \beta$ and tau is still unclear, several hypotheses have been proposed [18]. In order to develop new therapies and since it is possible that changes in phosphokinases could be involved in tau phosporylation, many protein kinase such as glycogen synthase kinase $3 \beta$ (GSK3 $\beta$ ), cyclin-dependent kinase 5 (CDK5), extracellular signalrelated kinase 2 (ERK2), have been investigated as targets of treatments to reduce tau phosphorylation. Therefore, the cascade which leads to the formation of phosphorylated tau may contribute to synaptic and neuronal loss and preliminary work which aimed to reduce tau phosphorylation has shown that tau kinase inhibitors block neurofibrillary tangles formation in tau transgenic mouse but clinical testings are still under investigation [19].

$\mathrm{AD}$ has a widespread and complex molecular background, and different molecular changes occur in the disorder. Therefore, it has been suggested that there is no single molecular event which leads to AD but it is caused by different and multiple parallel mechanisms. Recently new findings supported the amyloid hypothesis [20], but also the tau pathology. In addition, important information and experimental evidence have emerged. One of these is the mitochondrial dysfunction with degeneration of mitochondria in neurons [21], but also phenomena such as inflammatory mechanisms, oxidative stress [22], vascular homeostasis, lipid metabolism [4] followed also by alterations in energy metabolism and antioxidant defense system.

\section{Genetic of Alzheimer's disease}

Genetically, AD is a complex and heterogeneous disorder which involves a combination of genes that need to be identified and validated. Additionally, the genetic risk of developing $\mathrm{AD}$ is around 70\% [23] but familial $\mathrm{AD}$ accounts for less than $1 \%$ of the AD burden [7]. Generally, $\mathrm{AD}$ is divided into two forms: (1) early onset familial $\mathrm{AD}$ with Mendelian inheritance and (2) late onset AD named sporadic form, but it is necessary to emphasize that this historical dichotomy remains elusive for many aspects. However, among the genetic causes implicated in disease risk, three genes have been essential in our understanding of $\mathrm{AD}$ mechanism. Particularly, mutations in APP, presenilin-1 gene (PS1), and presenilin-2 gene (PS2) cause an autosomal dominant form of $\mathrm{AD}$ of young onset. These alterations are responsible for increase in $A \beta$ generation or in the levels of $A \beta 42$. Novel and fast high throughput approach such as DNA and RNA microarrays have led to the identification of multiple genes involved in different stages of $\mathrm{AD}$ [2], but it is important to avoid misidentification of false positive and 
to use these methods with great rigor. The main AD risk and familial genes are reported in table 1 and in addition to PS1 and PS2 that affect the accumulation of $\beta$-amyloid protein several other genes may have a role in the clearance or uptake of $\mathrm{A} \beta$.

Recent studies indicate that the over-expression or some polymorphisms of phosphokinases, such as dualspecificity tyrosine phosphorylation-regulated kinase $1 \mathrm{~A}$ (DYRK1A) contribute to an early onset of neurofibrillary degeneration, $\beta$-amyloidosis, neuronal loss [24] and this gene might be associated to the $A \beta$ production and tau phosphorilation [25].

Apolipoprotein E (APOE) localized on chromosome 19 is the major genetic risk factor that account for the late onset $\mathrm{AD}$; in particular the E4 variant (APOE4) of APOE gene is particularly important for sporadic AD but APOE4 is also associated with an earlier onset of the disease $[26,27]$. Three majors alleles (E2, E3, E4) are present on the chromosome but subjects carrying the E4 allele have increased amyloid deposition and recently it has been shown that the E4 allele affects memory and executive function [28]. APOE4 is the most reliable locus for AD but recent genome wide association studies (GWAS) have demonstrated other risk loci, in particular a study of 16000 individuals showed association with loci of clusterin (CLU) and phosphatidylinositol-binding clathrin assembly protein (PICALM) genes [29]. Functionally, CLU is involved in clearance and aggregation of $A \beta$ but also in $A \beta$ fibrillization [30,31]. PICALM plays a role in clathrin-mediated endocytosis [32], synaptic transmission, and in the removal of apoptotic cells $[33,34]$.

To date, several GWAS have been performed with several genes implicated in $\mathrm{AD}$ risk and progression rate and it is established by an emerging consensus that common genetic variation plays an important role in the etiology of AD. However, even though GWAS are critical in defining rare sequence variants that predispose to both early and late onset forms of $\mathrm{AD}$, it is necessary to replicate genetic associations which would require case/control comparison of several hundreds of individuals.

The first considerable finding based on large scale sequencing technologies was GRB2-associated binding protein 2 (GAB2). GAB2 binds growth factor receptorbound protein 2 (GRB2), which in turn can bind APP and both presenilins [35] but GAB2 is also associated with increased tau phosphorylation and its effect is most pronounced on carriers of the APOE4 allele [36]. In addition, new significant susceptibility loci are the complement receptor 1 gene (CR1) [37], a key inflammatory receptor protein activated in $\mathrm{AD}$ [38] and the bridging integrator 1 gene (BIN1) [39], which encodes an adaptor protein involved in receptor mediated endocytosis [40]. Interestingly, CLU, CR1 and PICALM have received much attention because supported by independent follow up studies [41].

The latest contribution to identify new susceptibility loci through GWAS was made by the Genetic and Environmental Risk in Alzheimer's Disease Consortium 1 (GERAD1) which showed ATP-binding cassette, subfamily A, member 7 (ABCA7) and membrane-spanning 4A (MS4A) gene cluster being two new AD associated loci. Further, the same study revealed genome-wide significance for CD2-associated protein (CD2AP), encoding ephrin receptor A1 (EPHA1) and Siglec-3 (CD33) that is a member of the sialic-acid-binding immunoglobulin-like lectins family and these three loci consisted in a followup indicative of association with AD [42].

Noticeably, other robust results come from the Alzheimer Disease Genetics Consortium (ADGC) that performed GWAS of late onset AD and accordingly we have now overall ten late onset AD susceptibility loci (APOE, CR1, CLU, PICALM, BIN1, EPHA1, MS4A, CD33, CD2AP and $\mathrm{ABCA7}$ ) that enhance our understanding of the genetic architecture of AD [43]. Other genes that could be considered to have a potential relevance in the risk for AD are genetic variants involved in inflammation. Notably, interleukins (IL1A, IL1B, and IL6) are one of the strongest evidence of inflammatory agents that increase the risk of $\mathrm{AD}$ and significant polymorphisms are implicated in $\mathrm{AD}$ as demonstrated in several case/control studies [44]. It is widely accepted that genetic variation is important for the pathogenesis of $\mathrm{AD}$ and several researchers have tried to find out polymorphisms that may be related with it but convincing outcomes have not emerged yet. However, very recently Kennedy et al. reported that the brain-derived neurotrophic factor (BDNF) Val66Met (rs6265) polymorphism may have a genetic susceptibility mechanism for AD. These findings highlighted that the effect of BDNF Val66Met polymorphism confers risk of AD in an agedependent manner [45]. In addition, genetic variants in the sortilin-related receptor (SORL1), involved in trafficking of APP, increases the risk of AD. Recent data of genetic associations suggest that changes in one of its homologs, the sortilin-related VPS10 domain containing receptor 1 (SORCS1) may affect the risk of AD [46]. It is also interesting to mention a new study that analyzed the region of APOE and of the adjacent gene translocase of outer mitochondrial membrane 40 (TOMM40) that are strongly associated with AD. Two poliymorphisms for APOE and TOMM40, respectively rs429358 and rs2075650, reached genome wide significance and showed association with $\mathrm{A} \beta$ and $t-\operatorname{tau} / \mathrm{A} \beta$ ratios [47]. In order to investigate the genetic associations between the inflammatory mediator tumor necrosis factor- $\alpha$ (TNF- $\alpha$ ) and AD, a detailed meta-analysis of polymorphisms in TNF- $\alpha$ was reviewed by Caruso et al. The study analyzed the association between 5 TNF- $\alpha$ 
Table 1 Schematic Overview of Major Alzheimer's Disease Gene

\begin{tabular}{|c|c|c|}
\hline Familial Genes & Locus & Functions \\
\hline$\overline{A P P}$ & $21 \mathrm{q} 21.3$ & $\begin{array}{l}\text { APP gene encodes a membrane protein cleaved by secretase. Mutations in App locus causes autosomal dominant early } \\
\text { onset AD and cerebroarterial amyloidosis. }\end{array}$ \\
\hline PS1 & $14 q 24.2$ & $\begin{array}{l}\text { PS1 is involved in APP processing and mutations can interfere the production of A } 42 \text { and to form plaques. Numerous } \\
\text { alternatively spliced transcript variants encoding different isoforms have been identified for this gene. }\end{array}$ \\
\hline PS2 & $1 \mathrm{q} 42.13$ & Regulate APP processing as a part of the $\alpha$-secretase complex. Familial mutations can change the production of A $\beta 42$. \\
\hline \multicolumn{3}{|l|}{ Risk Genes } \\
\hline APOE & $19 q 13.32$ & $\begin{array}{l}\text { ApoE regulates the normal catabolism of triglyceride-rich lipoprotein constituents. APOE binds A } \beta \text { and it is involved in } \\
\text { A } \beta \text { clearance. Subjects carrying the E4 allele have an increased amyloid burden. }\end{array}$ \\
\hline
\end{tabular}

TAU 17q21.31 The transcript undergoes complex alternative splicing and tau exists as six splice isoforms. The mutations can alter microtubule binding efficacy.

DYRK1A 21q22.13 DYRK1A is localized in the critical region of chromosome 21 and is involved in tau and APP phosphorylation. Firstly the activity is upregulated by $A \beta$ and APP phosphorylation result in increased amyloidogenic processing with BACE interaction.

GSK3ß

3q13.33 The overexpression of this gene may be relevant for AD. GSK-3 phosphorylates tau and presenilin-1, which are involved in the development of AD. The phosphorylation of tau leads to tangle formation and APP cleavage products can activate GSK3 $\beta$ resulting increased tau phosphorylation.

\section{New GWAS}

Genes

CLU

PICALM

CR1

BIN1

ABCA7

MS4A

CD2AP

EPHA1

CD33 8p21.1 Clusterin is a chaperone molecule involved in clearence, aggregation and fibrillization of A $\mathrm{B}$. It is associated with the progression of $A D$.

11q14.2 Phosphatidylinositol binding clathrin assembly protein is associated with an increased risk of developing AD. PICALM plays a role in synaptic trasmission and may be involved in $A \beta$ clearence. The protein is present in endosomes connected with $A D$.

1q32.2 This gene is a member of the receptors of complement activation (RCA) family, precisely the complement C3b protein a key inflammatory protein activated in AD.

2q14.3 This gene encodes several isoforms of a nucleocytoplasmic adaptor protein involved in endocytosis. BIN1 could have an effect on $A \beta$ production and/or the clearance of $A \beta$.

19p13.3 This gene is a member of the superfamily of ATP-binding cassette (ABC) transporters and is highly expressed in brain, particularly in the microglia. ABCA7 inhibit $\beta$-amyloid secretion in cultured cells overexpressing APP.

11q12.2 The genes in the MS4A cluster are locolized on chromosome 11 and encode proteins with at least 4 potential transmembrane domains but do not have specific function yet.

6p12.3 C2AP encodes a scaffolding molecule that regulates the actin cytoskeleton and is involved in the regulation of receptormediated endocytosis.

$7 q 35$ EPHA1 is a member of the ephrin receptor subfamily of the protein-tyrosine kinase family. It is implicated in synaptic development and plasticity but also axon guidance. Other functions have been proposed.

19q13.41 CD33 molecule belongs to the family of sialic acid-binding, immunoglobulinlike lectins. CD33 regulate the functions in the adaptive and innate immune systems both involved into the inflammatory reactions observed in the brains of $A D$ patients. 
polymorphisms (-850, -308, -863, -238, and -1031) and AD and suggested a specific genetic effect of the -850 single nucleotide polymorphism (SNP) on the AD risk [48].

Finally, it is important to provide further genetic biomarkers for the future but at the same time is vital to develop an accurate biomarker panel able to predict AD risk but also identify the pathways involved in the disorder and potential drug targets.

\section{Biochemical markers for AD}

The CSF is an optimal source of AD biomarkers because it is in intimate contact with the extracellular space of the brain and can reflect biochemical changes and metabolic processes that occur in the course of the disease. The diagnostic use of CSF for AD is difficult because collecting CSF requires an invasive treatment by lumbar puncture. Thus, other body fluids may be useful for AD diagnosis but also to monitor the progression of the disorder and to search for biomarkers. Metabolic products and proteins such as albumin, immunoglobulins, transferrin and $\alpha 2$ macroglobulin can be detect in plasma or serum but requires very sensitive methods because their total content especially in serum is very low.

\subsection{Experimental approach to detect biochemical markers} in $A D$

Here we will provide a brief overview on the main methods that are currently used to enhance our understanding of $\mathrm{AD}$ and develop a biomarkers panel that could support clinical diagnosis. All these methods have advantages and disadvantages but it is important to standardize the entire workflow including sample processing and instrument setup. There are several issues in the search of AD biomarker discovery but in order to develop novel diagnostic strategies to diagnose and monitor AD progression it is essential to complement 'omics' disciplines with other traditional methods. The major proteomics biomarker discovery methods are two-dimensional gel electrophoresis (2-DE) that provide high sensitivity and mass spectrometry (MS) based techniques.

For instance, the characterization of the human CSF proteome typically requires combined approach such as 2D-polyacrylamide gel electrophoresis (PAGE) with matrix-assisted laser desorption/ionization combined with time of flight MS (MALDI-TOF-MS) and liquid chromatography combined with electrospray ionization (LC-ESIMS). Also the technology surrounding biomarker analysis in blood is developing rapidly and the increasing need of biomarkers in clinical trials has been faciliated by high throughput multiplex platform $[49,50]$. In addtion, there are several AD biomarker studies with surface enhanced laser desorption ionization (SELDI)-TOF-MS which provides an high throughput protein expression profile analysis [51]. Furthermore, most of proteomics methods for protein quantification are based on chemical labelling with stable isotope and different labelling strategies are available, such as isotope tagged relative and absolute quantitation (iTRAQ) [52], tandem mass tag (TMT) [53], isotope coded affinity tag (ICAT) [54] and isotope coded protein label (ICPL) [55]. In addition, antibody array provide an high throughput method to analize multiple biomarkers simultaneously. This assay, which was based on xMAP technology (Luminex, Austin, TX, USA) will replace enzyme linked immunosorbent assays (ELISA) in the measurement of the biomarkers.

Molecular imaging techniques improve diagnostic accuracy by reflecting brain function and single positron emission computed tomography (SPECT), PET, MRI provide relevant clinical results. PET using Pittsburg compound (PIB) allows the direct visualization of $\mathrm{A} \beta$ plaque burden in the brain when the patients are still alive. Structural MRI provide measures of brain atrophy [56] related to the degree of cognitive impairment [57]. Also the evolution of computational approaches could help the discovery of biomarkers that cause the disorder and the bioinformatics tools may reveal the high complexity of pathological mechanisms evidencing the protein networks that lead to AD.

\subsection{CSF Biomarkers}

The concentrations of several proteins in CSF reflects with good diagnostic accuracy the pathophysiological features of the disease. Particularly, there is an "AD signature" in the CSF [58] because the measurements of numerous studies have found that patients with AD have a marked increase in CSF levels of total tau ( $t$-tau) and phosphorylated tau (p-tau) but characteristically show a reduction in A $\beta 42$. Combining the various CSF markers may be useful to differentiate different forms of dementia [59] and to predict the conversion from mild cognitive impairment $(\mathrm{MCI})$ to $\mathrm{AD}$. In this perspective, Trojanowski et al. with targeted proteomic screen revealed novel CSF biomarkers that can improve the distinction between $\mathrm{AD}$ and non $\mathrm{AD}$ cases. Specifically, they identified some analytes including $\mathrm{A} \beta 42$, resistin and thrombospondin-1 that are associated with $\mathrm{AD}$ [60]. In 2010, the same author argued that $A \beta 42$ is the most sensitive CSF biomarker for AD, with a sensitivity of $96.4 \%$ [61]. In addition, even though the combined analysis of $A \beta 42$, $t$-tau and $p$-tau are approved in clinical diagnostic tools, some researchers have asserted that has less predictive value in preclinical testing [62].

Recent studies have been focused on the investigation of truncated $A \beta$ isoforms and experimental data showed a novel pathway where short isoforms are generated by $\beta$ secretase and $\alpha$-secretase and long isoforms are produced by $\gamma$-secretase [63]. Interestingly, the levels of $A \beta$ (1-37, $-38,-39,-40,-42)$ gave a $91 \%$ sensitivity and a $64 \%$ specificity in predicting the development of AD from MCI 
during a follow up study [64]. Other CSF biomarkers that may be valuable for AD are neuronal and synaptic proteins. Notably, visinin-like protein 1 (VLP-1), a calcium sensor protein expressed in high abundance in neurons, was found markedly increased in CSF of patients with AD [65]. Furthermore, an immunoassay for growth associated protein (GAP43), revealed increased levels of the protein in CSF from patients with AD [66]. AD specific changes in the CSF proteome have been found in many studies. For istance, variations that have been reported in $\mathrm{AD}$ include altered levels of $\alpha$-1-antitrypsin, $\alpha-1 b$ glycoprotein, APOA-I, APOE, retinol binding protein, vitamin D-binding protein, prostaglandin $\mathrm{H} 2 \mathrm{D}$ isomerase and transthyretin (TTR) [67-72]. Interestingly, the presence of APOE4 allele is associated with increased deposition of $A \beta 42$ in the brain and decreased CSF level of A $\beta 42$ [73].

Emerging evidence indicates that oxidative damage is involved in AD. For instance, lipid peroxidation affects the generation of F2-isoprostanes whose levels are often increased in the CSF of patients with AD [74]. Lipid peroxidation products have been found in brain, CSF and plasma from mammalian models with AD [75] and GWAS have identified new risk genes that are linked to lipid metabolism such as CLU also known as apolipoprotein J (ApoJ) [29].

Although there are several inflammatory biomarkers reported in CSF, none of them can be considered to have diagnostic or predictive value. However, some candidate CSF biomarkers of inflammation that showed increased levels in AD are TNF- $\alpha$ [76], monocyte chemotactic protein-1 [77], interferon $\gamma$-inducible protein 10, IL-8 [78], IL6 [79], transforming growth factor- $\beta$ (TGF $\beta$ ) [80], vascular endothelial growth factor (VEGF) [79] and others but detecting changes of inflammatory molecules in CSF require larger scale of replication in cohorts of patients because of their low levels in the CSF.

Recently, using an unbiased proteomics approach (2DDIGE LC-MS/MS), Fagan and co-workers identified four novel CSF biomarkers for AD (NrCAM, YKL-40, chromogranin A, carnosinase I). Notably, these markers can improve the diagnostic panel accuracy especially of $A \beta 42$ and tau and may have the utility to better discriminate early symptomatic AD from cognitive normalcy but also other dementing conditions [81].

In a future perspective on the progress of CSF examination it might be useful to focus on post-translational modifications that have not been widely studied in CSF proteome studies. For example, phosphorylation is the most common tau post-translational modification described but other post-translational modifications have received much less attention and it is likely that additional modifications are required for the formation of tau aggregates. Various kinases and phosphatases regulate tau phosphorylation [82] suggesting their potential involvement in the development of new therapeutic drugs for AD.

Currently, in CSF several candidate biomarkers have been found but their applicability to improve the diagnosis of AD or to discover new drug targets have not established yet. However, numerous studies have been shown that the most promising biomarkers for AD in CSF include the combined analysis of $A \beta 42$, $t$-tatu and $\mathrm{p}$-tau that allows sensitive, reliable and specific diagnosis of $\mathrm{AD}$ identifying prodromal $\mathrm{AD}$ in cases of $\mathrm{MCI}$.

\subsection{Biomarkers in blood}

In the last years many efforts were done to find disease specific and reliable blood biomarkers and different candidate such as $\alpha 1$-antitrypsin, complement factor $\mathrm{H}, \alpha-2$ macroglobulin, ApoJ and ApoA-1 have been proposed. However, the verification of changes in the levels of these molecules is difficult to verify in independent studies. In addition, it is significant to note that in the search for blood biomarkers correlated with AD the identification should be performed on the strength of accepted CSF markers, such as $A \beta$ and tau related biomarkers. Furthermore, several documented evidence suggested that in the blood there is a protein signature related with $\mathrm{AD}$ but also in some way a transcript signature that might be relevant to predict and monitor the disease and increase reliability of the diagnosis. Although the study of the transcriptome as a potential source of biomarkers in blood could have many advantages the evidence of a transcript signature in blood are scant and its utility in AD diagnosis remains to be clarified. Table 2 lists the main biomarkers related to $\mathrm{AD}$ mentioned in this review.

In 2007, with a combined multivariate analysis of 18 plasma signaling and inflammatory proteins (e.g. IL- $1 \alpha$, IL-3, TNF- $\alpha$ ) Ray and colleagues identified a profile that was indicative of $A D$ and predicted $A D$ in patients with MCI [50]. Plasma A $\beta$ was examined in different studies but provided opposing data because A $\beta$ binds several plasma proteins resulting in epitope masking and other analytical interferences [83]. The role of inflammation with microglia activation is believed to play a role in $\mathrm{AD}$ pathogenesis but the presence of inflammatory markers in serum or plasma is unclear. Inflammatory molecules, such as IL-1 $\beta$, TNF- $\alpha$, IL-6, C-reactive protein, a1-antichymotrypsin showed contrasting results [84]. Seshadri and colleagues in the Framingham study observed that high levels of peripheral blood mononuclear cell (PBMC) of the inflammatory cytokines such as IL-1 or TNF- $\alpha$ are associated with an increased risk of developing $\mathrm{AD}[85]$.

Noteworthy, Teunissen et al. evaluated 29 serum biomarkers for inflammation, cholesterol and homocysteine metabolism, and brain specific proteins. This panel 
Table 2 Main pathway and biomarkers AD related cited in this review

\begin{tabular}{|c|c|c|}
\hline Pathway & Biomarker & Potential association with $A D$ \\
\hline \multirow[t]{6}{*}{$\begin{array}{l}\text { Signal } \\
\text { transduction }\end{array}$} & GSK3 $\beta$ & $\begin{array}{l}\text { GSK3 } \beta \text { integrates a variety of intracellular and extracellular pathways and appears to be increased in the AD } \\
\text { brain. GSK3 } \beta \text { is regulated by phosphorylation and is the major tau kinases. }\end{array}$ \\
\hline & CDK5 & $\begin{array}{l}\text { Cdk5 plays a role in processes of neural development, synaptic signalling, learning and can influence tau } \\
\text { phosphorylation indirectly via regulation of GSK3 } \beta \text {. }\end{array}$ \\
\hline & ERK2 & $\begin{array}{l}\text { The phosphorylation of tau by ERK2 induces tau to acquire biochemical properties of AD. ERK2 was detected } \\
\text { in neurofibrillary tangles. }\end{array}$ \\
\hline & DYRK1A & $\begin{array}{l}\text { Dyrk1A is abnormally expressed in AD and recently it has been found to be associated with neurofibrillary } \\
\text { tangles in sporadic AD. }\end{array}$ \\
\hline & PKC & $\begin{array}{l}\text { PKC has been implicated in memory mechanisms and is also involved in the processing of APP. The activators } \\
\text { of PKC lead to increased processing of APP by the } \alpha \text {-secretase pathway. }\end{array}$ \\
\hline & VLP-1 & $\begin{array}{l}\text { Visinin-like protein } 1 \text { concentration is significantly altered in the CSF of AD patients and ia is associated with } \\
\text { fibrillar tangles in AD brains. }\end{array}$ \\
\hline $\begin{array}{l}\text { Oxidative } \\
\text { stress }\end{array}$ & F2-isoprostanes & Incresed levels of F2-isoprostanes are found in AD plasma and CSF. \\
\hline \multirow[t]{8}{*}{ Inflammation } & Interleukins & $\begin{array}{l}\text { Interleukins are consistently detected in the brains of } A D \text { and polymorphisms are implicated in AD. The activity } \\
\text { in } A D \text { contributes to synaptic dysfunction and loss, and later, neuronal death. }\end{array}$ \\
\hline & TNF- $\alpha$ & $\begin{array}{l}\text { TNF- } \alpha \text { has a central role in AD pathogenesis. The levels are increased in CSF and correlated with clinical } \\
\text { deterioration. }\end{array}$ \\
\hline & $\begin{array}{l}\text { C-reactive } \\
\text { protein }\end{array}$ & $\begin{array}{l}\text { C-reactive protein has been found to be associated with } A D \text { in histopathological and longitudinal studies. It is } \\
\text { associated with increased risk of AD. }\end{array}$ \\
\hline & $\begin{array}{l}\alpha-1- \\
\text { antichymotrypsin }\end{array}$ & $\begin{array}{l}\alpha \text {-1-antichymotrypsin participates in the inflammatory cascade of } A D \text { and enhances the formation of amyloid- } \\
\text { fibrils. }\end{array}$ \\
\hline & $\begin{array}{l}\alpha 2- \\
\text { macroglobulin }\end{array}$ & $\begin{array}{l}\alpha 2 \text {-macroglobulin has an important role in AD etiopathology. The main ability is to mediate the clearance and } \\
\text { degradation of } A \beta \text {. }\end{array}$ \\
\hline & Homocysteine & Hyperhomocysteinaemia is a risk factor for $A D$ and mental decline. \\
\hline & ICAM-1 & $\begin{array}{l}\text { ICAM-1 is expressed on cerebrovascular endothelium and neuritic plaques in brain of AD patients and seems } \\
\text { to be implicated in the process of neuro-degeneration. }\end{array}$ \\
\hline & VCAM-1 & $\begin{array}{l}\text { Abnormal levels of VCAM-1 levels have been found in individuals with AD as well as other cell adhesion } \\
\text { molecules. }\end{array}$ \\
\hline \multirow[t]{2}{*}{$\begin{array}{l}\text { Lipid } \\
\text { metabolism }\end{array}$} & Total cholesterol & High concentration of serum cholesterol is associated with increased risk of incident AD. \\
\hline & APOE & APOE E2, E3, and E4 alleles alter the likelihood of developing AD and cerebral amyloid angiopathy. \\
\hline
\end{tabular}

including IL-6 receptor, cysteine and cholesterol demonstrated to be a suitable combination to discriminate AD from controls [86]. Several evidence have documented that cholesterol metabolism plays a role in AD [87]. Total serum cholesterol may be a marker of AD because high concentration of serum cholesterol is associated with increased risk of incident $\mathrm{AD}$ [88]. In the brain monocytes migrate through the blood-brain barrier (BBB) interacting with specific cell adhesion molecules (CAM). Several CAMs on monocytes are activated during the inflammatory and neurodegenerative response. Therefore, these could be useful as biomarkers in AD. Humpel and 
co-workers reported that monocytic ICAM-3 and P-selectin are significantly reduced in AD patients [89].

A growing body of evidence demonstrates that plasma concentration of vascular cell adhesion molecule-1 (VCAM-1) and intercellular adhesion molecule-1 (ICAM$1)$ are increased in $\mathrm{AD}$. In addition, endothelial vasodilatory such as endothelin (ET-1), adrenomedullin (ADM), and atrial natriuretic peptide (ANP), as well as sphingolipids are altered in mild $\mathrm{AD}$ and $\mathrm{MCI}$ suggesting sensitivity of these biomarkers for early detection and diagnosis [90].

Another potential biomarker important for AD diagnosis because involved in tau phosphorylation, is the protein kinase $\mathrm{C}$ (PKC). The PKC function is involved in memory processes in animal models [91] and appears altered in red blood cells and lymphocytes of AD patients [92]. By inhibiting GSK3 3 , PKC reduces tau phosphorylation and neurofibrillary tangles formation [93] representing a potential target for the development of disease modifying drugs.

In summary, according to the diagnostic and prognostic point of view, the most promising markers in $\mathrm{AD}$ diagnosis to be associated with $A \beta$ and tau include $\alpha 1$ antitrypsin, $\alpha$-2-macroglobulin, apo lipoproteins and TTR.

Conclusively, it seems clear that the combinations of different biomarkers can improve the diagnosis of AD but the markers in the CSF and blood are not enough and other molecules are abnormally processed in AD.

Overall, by analyzing 13 different brain regions of AD affected patients Korolainen et al. demonstrated changes in 93 proteins in association with the disease [94]. These proteins showed quantitative differences and/or posttranslational modifications in cognitive impairment in early and late AD. According to the gene ontology (GO) classification these proteins are involved in oxidationreduction (12), glycolysis (8), transport (8), metabolic processes (7), protein folding (6), the response to unfolded proteins (5) and cell proliferation (5). 56 of them are cytoplasmic, 28 mitochondrial, 20 nuclear and 16 cytosolic proteins. Finally, three of them are synaptic proteins (synaptosomal-associated protein-25 (SNAP-25), synaptotagmin and syntaxin-binding protein) which present altered expression or modification.

\section{Concluding remarks}

We have highlighted different biomarkers that may be important for the detection and differential diagnosis of $\mathrm{AD}$. It is clear that many questions remain to be answered especially because we know only few evidence about the relationships between these biomarkers and the development of the disease. Although the combined analysis of $A \beta$, $t$-tau and $p$-tau can be used to diagnose AD, it is important to characterize the core of biomarkers involved in the prodromal phase of $\mathrm{AD}$ but also in the presymptomatic stage of the disease. For this purpose only the combination of several biomarker derived from CSF and other body fluids will be efficacious to define a specific signature of $\mathrm{AD}$. The measurement of $\mathrm{AD}$ biomarkers in the CSF or by structural and functional imaging and genetics methods improves diagnostic accuracy but also the prospect for blood based biomarkers is attractive. Taken together these tools have revealed the effective importance of molecular mechanism that contribute to pathological changes and neurodegeneration. For instance, these processes are oxidative stress, overproduction of reactive oxygen species, changes in ubiquitination, reorganization in the cytoskeletal proteins, production of misfolded protein and many others. Furthermore, it is important to implement common protocol and to standardize the ultrasensitive analytical methods for experimental design and generation data.

\section{Acknowledgements}

We would like to thank N. Sapere for critical reading of the manuscript and for helpful discussions. The authors are grateful to the Department of Health Sciences, University of Molise, Italy for the support.

\section{Author details}

'Department of Health Sciences, University of Molise, Campobasso, Italy. ${ }^{2}$ Department of Biochemistry and Molecular Biology, Institute of Human Virology-School of Medicine, University of Maryland, Baltimore, MD, USA. ${ }^{3}$ IRCCS Associazione Oasi Maria S.S., Institute for Research on Mental Retardation and Brain Aging, Troina, Enna, Italy.

\section{Authors' contributions}

All the Authors drafted the manuscript and approved the final manuscript.

\section{Competing interests}

The authors declare that they have no competing interests.

Received: 3 August 2011 Accepted: 20 September 2011 Published: 20 September 2011

\section{References}

1. Alzheimer's Association: 2010 Alzheimer's disease facts and figures. Alzheimers Dement 2010, 6:158-94.

2. Ho L, Fivecoat H, Wang J, Pasinetti GM: Alzheimer's disease biomarker discovery in symptomatic and asymptomatic patients: experimental approaches and future clinical applications. Exp Gerontol 2010, 45:15-22.

3. Grimes DA, Schulz KF: Uses and abuses of screening tests. Lancet 2002, 359:881-4

4. Querfurth HW, LaFerla FM: Alzheimer's disease. N Engl J Med 2010, 362:329-44.

5. Spires-Jones TL, Stoothoff WH, de Calignon A, Jones PB, Hyman BT: Tau pathophysiology in neurodegeneration: a tangled issue. Trends Neurosci 2009, 32:150-9.

6. Hardy JA, Higgins GA: Alzheimer's disease: the amyloid cascade hypothesis. Science 1992, 256:184-185.

7. Blennow K, de Leon MJ, Zetterberg H: Alzheimer's disease. Lancet 2006, 368:387-403.

8. Zetterberg $H$, Andreasson U, Hansson O, Wu G, Sankaranarayanan S, Andersson ME, et al: Elevated cerebrospinal fluid BACE1 activity in incipient Alzheimer disease. Arch Neurol 2008, 65:1102-1107.

9. Zhong Z, Ewers M, Teipel S, Bürger K, Wallin A, Blennow K, et al: Levels of $\beta$-secretase (BACE1) in cerebrospinal fluid as a predictor of risk in mild cognitive impairment. Arch Gen Psychiatry 2007, 64:718-726.

10. Castellani RJ, Rolston RK, Smith MA: Alzheimer disease. Dis Mon 2010, 56:484-546.

11. Pimplikar SW: Reassessing the amyloid cascade hypothesis of Alzheimer's disease. Int J Biochem Cell Biol 2009, 41:1261-68. 
12. Zetterberg $H$, Blennow $K$, Hanse E: Amyloid beta and APP as biomarkers for Alzheimer's disease. Exp Gerontol 2010, 45:23-9.

13. Lescuyer P, Allard L, Zimmermann-Ivol CG, Burgess JA, Hughes-Frutiger S, Burkhard PR, et al: Identification of post-mortem cerebrospinal fluid proteins as potential biomarkers of ischemia and neurodegeneration. Proteomics 2004, 4:2234-2241

14. Finehout EJ, Franck Z, Relkin N, Lee KH: Proteomic analysis of cerebrospinal fluid changes related to postmortem interval. Clin Chem 2006, 52:1906-1913.

15. Hernandez F, Avila J: Tauopathies. Cell Mol Life Sci 2007, 64:2219-2233.

16. Hanger DP, Byers HL, Wray S, Leung KY, Saxton MJ, Seereeram A, et al: Novel phosphorylation sites in tau from Alzheimer brain support a role for casein kinase 1 in disease pathogenesis. J Biol Chem 2007, 282:23645-23654.

17. Meraz-Rios MA, Lira-De Leon Kl, Campos-Pena V, De Anda-Hernandez MA, Mena-Lopez R: Tau oligomers and aggregation in Alzheimer's disease. J Neurochem 2010, 112:1353-67.

18. Small SA, Duff K: Linking Abeta and tau in late-onset Alzheimer's disease: a dual pathway hypothesis. Neuron 2008, 60:534-42.

19. Takashima A: Amyloid-beta, tau, and dementia. J Alzheimers Dis 2009, 17:729-36.

20. Hardy J: The amyloid hypothesis for Alzheimer's disease: a critical reappraisal. J Neurochem 2009, 110:1129-1134.

21. Devi L, Anandatheerthavarada HK: Mitochondrial trafficking of APP and alpha synuclein: relevance to mitochondrial dysfunction in Alzheimer's and Parkinson's diseases. Biochim Biophys Acta 2010, 1802:11-19.

22. Mancuso C, Scapagnini G, Currò D, Giuffrida Stella AM, De Marco C, Butterfield DA, Calabrese V: Mitochondrial dysfunction, free radical generation and cellular stress response in neurodegenerative disorders. Front Biosci 2007, 12:1107-1123.

23. Gatz M, Reynolds CA, Fratiglioni L, Johansson B, Mortimer JA, Berg S Fiske $A$, et al: Role of genes and environments for explaining Alzheimer disease. Arch Gen Psychiatry 2006, 63:168-174.

24. Wegiel J, Gong CX, Hwang YW: The role of DYRK1A in neurodegenerative diseases. FEBS J 2011, 278:236-45

25. Kimura R, Kamino K, Yamamoto M, Nuripa A, Kida T, Kazui H, et al: The DYRK1A gene, encoded in chromosome 21 Down syndrome critical region, bridges between beta-amyloid production and tau phosphorylation in Alzheimer disease. Hum Mol Genet 2007, 16:15-23.

26. Strittmatter WJ, Roses AD: Apolipoprotein E and Alzheimer disease. Proc Natl Acad Sci USA 1995, 92:4725-4727

27. Corder EH, Saunders AM, Strittmatter WJ, Schmechel DE, Gaskell PC, Small GW, et al: Gene dose of apolipoprotein E type 4 allele and the risk of Alzheimer's disease in late onset families. Science 1993, 261:921-923.

28. Wolk DA, Dickerson BC, Alzheimer's Disease Neuroimaging Initiative: Apolipoprotein E (APOE) genotype has dissociable effects on memory and attentional-executive network function in Alzheimer disease. Proc Natl Acad Sci USA 2010, 107:10256-10261.

29. Harold D, Abraham R, Hollingworth P, Sims R, Gerrish A, Hamshere ML, et al: Genome-wide association study identifies variants at CLU and PICALM associated with Alzheimer's disease. Nature Genet 2009, 41:1088-93.

30. DeMattos RB, O'dell MA, Parsadanian M, Taylor JW, Harmony JA, Bales KR, et al: Clusterin promotes amyloid plaque formation and is critical for neuritic toxicity in a mouse model of Alzheimer's disease. Proc Natl Acad Sci USA 2002, 99:10843-10848.

31. DeMattos RB, Cirrito JR, Parsadanian M, May PC, O'Dell MA, Taylor JW: ApoE and clusterin cooperatively suppress Abeta levels and deposition: Evidence that ApoE regulates extracellular Abeta metabolism in vivo. Neuron 2004, 41:193-202

32. Tebar F, Bohlander SK, Sorkin A: Clathrin assembly lymphoid myeloid leukemia (CALM) protein: Localization in endocytic-coated pits, interactions with clathrin, and the impact of overexpression on clathrinmediated traffic. Mol Biol Cell 1999, 10:2687-2702.

33. Harel A, Wu F, Mattson MP, Morris CM, Yao PJ: Evidence for CALM in directing VAMP2 trafficking. Traffic 2008, 9:417-429.

34. Yao PJ, Petralia RS, Bushlin I, Wang Y, Furukawa K: Synaptic distribution of the endocytic accessory proteins AP180 and CALM. J Comp Neurol 2005, 481:58-69.

35. Nizzari M, Venezia V, Repetto E, Caorsi V, Magrassi R, Gagliani MC, et al: Amyloid precursor protein and Presenilin1 interact with the adaptor GRB2 and modulate ERK 1,2 signaling. J Biol Chem 2007, 282:13833-13844.
36. Reiman EM, Webster JA, Myers AJ, Hardy J, Dunckley T, Zismann VL, et al: GAB2 alleles modify Alzheimer's risk in APOE epsilon4 carriers. Neuron 2007, 54:713-720.

37. Corneveaux JJ, Myers AJ, Allen AN, Pruzin JJ, Ramirez M, Engel A, et al: Association of CR1, CLU and PICALM with Alzheimer's disease in a cohort of clinically characterized and neuropathologically verified individuals. Hum Mol Genet 2010, 19:3295-3301.

38. Khera R, Das N: Complement Receptor 1: Disease associations and therapeutic implications. Mol Immunol 2009, 46:761-772.

39. Seshadri S, Fitzpatrick AL, Ikram MA, DeStefano AL, Gudnason V, Boada M, et al: Genome-wide analysis of genetic loci associated with Alzheimer disease. JAMA 2010, 303:1832-1840.

40. Pant S, Sharma M, Patel K, Caplan S, Carr CM, Grant BD: AMPH-1/ Amphiphysin/Bin1 functions with RME-1/Ehd1 in endocytic recycling. Nat Cell Biol 2009, 11:1399-1410.

41. Carrasquillo MM, Belbin O, Hunter TA, Ma L, Bisceglio GD, Zou F, et al: Replication of CLU, CR1, and PICALM associations with alzheimer disease. Arch Neurol 2010, 67:961-964.

42. Hollingworth P, Harold D, Sims R, Gerrish A, Lambert JC, Carrasquillo MM, et al: Common variants at ABCA7, MS4A6A/MS4A4E, EPHA1, CD33 and CD2AP are associated with Alzheimer's disease. Nat Genet 2011, 43:429-35.

43. Naj AC, Jun G, Beecham GW, Wang LS, Vardarajan BN, Buros J, et al: Common variants at MS4A4/MS4A6E, CD2AP, CD33 and EPHA1 are associated with late-onset Alzheimer's disease. Nat Genet 2011, 43:436-41.

44. Du Y, Dodel RC, Eastwood BJ, Bales KR, Gao F, Lohmüller F, et al: Association of an interleukin 1 alpha polymorphism with Alzheimer's disease. Neurology 2000, 55:480-483.

45. Voineskos AN, Lerch JP, Felsky D, Shaikh S, Rajji TK, Miranda D, et al: The brain-derived neurotrophic factor Val66Met polymorphism and prediction of neural risk for Alzheimer disease. Arch Gen Psychiatry 2011, 68:198-206.

46. Reitz C, Tokuhiro S, Clark LN, Conrad C, Vonsattel JP, Hazrati LN, et al: SORCS1 alters amyloid precursor protein processing and variants may increase Alzheimer's disease risk. Ann Neurol 2011, 69:47-64.

47. Kim S, Swaminathan S, Shen L, Risacher SL, Nho K, Foroud T, et al: Genome-wide association study of CSF biomarkers Abeta1-42, t-tau, and p-tau181p in the ADNI cohort. Neurology 2011, 76:69-79.

48. Di Bona D, Candore G, Franceschi C, Licastro F, Colonna-Romano G, Cammà $C$, et al: Systematic review by meta-analyses on the possible role of TNF-alpha polymorphisms in association with Alzheimer's disease. Brain Res Rev 2009, 61:60-68.

49. Shaw LM, Vanderstichele $H$, Knapik-Czajka M, Clark CM, Aisen PS, Petersen RC, et al: Cerebrospinal fluid biomarker signature in Alzheimer's disease neuroimaging initiative subjects. Ann Neurol 2009, 65:403-413.

50. Ray S, Britschgi M, Herbert C, Takeda-Uchimura Y, Boxer A, Blennow K, et al: Classification and prediction of clinical Alzheimer's diagnosis based on plasma signaling proteins. Nat Med 2007, 13:1359-1362.

51. Qin W, Ho L, Wang J, Peskind E, Pasinetti GM: S100A7, a novel Alzheimer's disease biomarker with non-amyloidogenic alpha-secretase activity acts via selective promotion of ADAM-10. PLoS One 2009, 4:e4183.

52. Ross PL, Huang YN, Marchese JN, Williamson B, Parker K, Hattan S, et al: Multiplexed protein quantitation in Saccharomyces cerevisiae using amine-reactive isobaric tagging reagents. Mol Cell Proteomics 2004, 3:1154-69.

53. Thompson A, Schäfer J, Kuhn K, Kienle S, Schwarz J, Schmidt G, et al: Tandem mass tags: a novel quantification strategy for comparative analysis of complex protein mixtures by MS/MS. Anal Chem 2003, 75:1895-904.

54. Gygi SP, Rist B, Gerber SA, Turecek F, Gelb MH, Aebersold R: Quantitative analysis of complex protein mixtures using isotope-coded affinity tags. Nat Biotechnol 1999, 17:994-999.

55. Schmidt A, Kellermann J, Lottspeich F: novel strategy for quantitative proteomics using isotope-coded protein labels. A Proteomics 2005, 5:4-15.

56. Vemuri $P$, Gunter JL, Senjem ML, Whitwell JL, Kantarci K, Knopman DS, et al: Alzheimer's disease diagnosis in individual subjects using structural MR images: validation studies. Neuroimage 2008, 39:1186-97.

57. Hua X, Leow AD, Parikshak N, Lee S, Chiang MC, Toga AW, et al: Tensorbased morphometry as a neuroimaging biomarker for Alzheimer's disease: an MRI study of $676 \mathrm{AD}, \mathrm{MCl}$, and normal subjects. Neuroimage 2008, 43:458-69. 
58. Forlenza OV, Diniz BS, Gattaz WF: Diagnosis and biomarkers of predementia in Alzheimer's disease. BMC Med 2010, 8:89.

59. Welge V, Fiege O, Lewczuk P, Mollenhauer B, Esselmann H, Klafki HW, et al: Combined CSF tau, p-tau181 and amyloid-beta 38/40/42 for diagnosing Alzheimer's disease. Journal of Neural Transmission 2009, 116:203-12.

60. Hu WT, Chen-Plotkin A, Arnold SE, Grossman M, Clark CM, Shaw LM, et al: Novel CSF biomarkers for Alzheimer's disease and mild cognitive impairment. Acta Neuropathol 2010, 119:669-78.

61. Trojanowski JQ, Vandeerstichele H, Korecka M, Clark CM, Aisen PS, Petersen RC, et al: Update on the biomarker core of the Alzheimer's Disease Neuroimaging Initiative subjects. Alzheimers Dement 2010, 6:230-238

62. Mattsson N, Zetterberg H: Alzheimer's disease and CSF biomarkers: key challenges for broad clinical applications. Biomark Med 2009, 3:735-737.

63. Portelius E, Price E, Brinkmalm G, Stiteler M, Olsson M, Persson R, et al: A novel pathway for amyloid precursor protein processing. Neurobiol Aging 2011, 32:1090-1098.

64. Höglund $\mathrm{K}$, Hansson O, Buchhave $\mathrm{P}$, Zetterberg H, Lewczuk P, Londos E, et al: Prediction of Alzheimer's disease using a cerebrospinal fluid pattern of C-terminally truncated beta-amyloid peptides. Neurodegener Dis 2008, 5:268-76.

65. Lee JM, Blennow K, Andreasen N, Laterza O, Modur V, Olander J, et al: The brain injury biomarker VLP-1 is increased in the cerebrospinal fluid of Alzheimer disease patients. Clin Chem 2008, 54:1617-23.

66. Sjögren M, Davidsson P, Gottfries J, Vanderstichele H, Edman A, Vanmechelen $E$, et al: The cerebrospinal fluid levels of tau, growthassociated protein- 43 and soluble amyloid precursor protein correlate in Alzheimer's disease, reflecting a common pathophysiological process. Dement Geriatr Cogn Disord 2001, 12:257-64.

67. Hesse C, Nilsson CL, Blennow K, Davidsson P: Identification of the apolipoprotein E4 isoform in cerebrospinal fluid with preparative twodimensional electrophoresis and matrix assisted laser desorption/ ionization-time of flight-mass spectrometry. Electrophoresis 2001, 22:1834-1837.

68. Davidsson $\mathrm{P}$, Westman-Brinkmalm A, Nilsson $\mathrm{CL}$, Lindbjer $\mathrm{M}$, Paulson $\mathrm{L}$, et al: Proteome analysis of cerebrospinal fluid proteins in Alzheimer patients. Neuroreport 2002, 13:611-615.

69. Puchades M, Hansson SF, Nilsson CL, Andreasen N, Blennow K, Davidsson P. Proteomic studies of potential cerebrospinal fluid protein markers for Alzheimer's disease. Brain Res Mol Brain Res 2003, 118:140-146.

70. Korolainen MA, Nyman TA, Nyyssönen P, Hartikainen ES, Pirttilä T: Multiplexed proteomic analysis of oxidation and concentrations of cerebrospinal fluid proteins in Alzheimer disease. Clin Chem 2007, 53:657-65

71. Sihlbom C, Davidsson P, Sjögren M, Wahlund LO, Nilsson CL: Structural and quantitative comparison of cerebrospinal fluid glycoproteins in Alzheimer's disease patients and healthy individuals. Neurochem Res 2008, 33:1332-40.

72. Zetterberg H, Rüetschi U, Portelius E, Brinkmalm G, Andreasson U, Blennow K, Brinkmalm A: Clinical proteomics in neurodegenerative disorders. Acta Neurol Scand 2008, 118:1-11.

73. Vuletic S, Li G, Peskind ER, Kennedy H, Marcovina SM, Leverenz JB, et al: Apolipoprotein E highly correlates with AbetaPP- and tau-related markers in human cerebrospinal fluid. J Alzheimers Dis 2008, 15:409-17.

74. Montine TJ, Quinn J, Kaye J, Morrow JD: F(2)-isoprostanes as biomarkers of late-onset Alzheimer's disease. J Mol Neurosci 2007, 33:114-119.

75. Butterfield DA, Galvan V, Lange MB, Tang H, Sowell RA, Spilman P, et al: In vivo oxidative stress in brain of Alzheimer disease transgenic mice: requirement for methionine 35 in amyloid $\beta$-peptide of APP. Free Radic Biol Med 2010, 48:136-144.

76. Tarkowski E, Blennow K, Wallin A, Tarkowski A: Intracerebral production of tumor necrosis factor-alpha, a local neuroprotective agent, in Alzheimer disease and vascular dementia. J Clin Immunol 1999, 19:223-230.

77. Blasko I, Lederer W, Oberbauer H, Walch T, Kemmler G, Hinterhuber $H$, et al: Measurement of thirteen biological markers in CSF of patients with Alzheimer's disease and other dementias. Dement Geriatr Cogn Disord 2006, 21:9-15.

78. Galimberti D, Schoonenboom N, Scheltens P, Fenoglio C, Bouwman F,

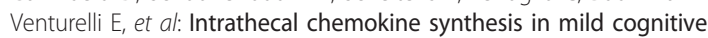
impairment and Alzheimer disease. Arch Neurol 2006, 63:538-43.
79. Gómez-Tortosa E, Gonzalo I, Fanjul S, Sainz MJ, Cantarero S, Cemillán C: Cerebrospinal fluid markers in dementia with lewy bodies compared with Alzheimer disease. Arch Neurol 2003, 60:1218-1222.

80. Rota E, Bellone G, Rocca P, Bergamasco B, Emanuelli G, Ferrero P: Increased intrathecal TGF-beta1, but not IL-12, IFN-gamma and IL-10 levels in Alzheimer's disease patients. Neurol Sci 2006, 27:33-39.

81. Perrin RJ, Craig-Schapiro R, Malone JP, Shah AR, Gilmore P, Davis AE, et al: Identification and validation of novel cerebrospinal fluid biomarkers for staging early Alzheimer's disease. PLoS One 2011, 6:e16032.

82. De-Paula VJ, Schaeffer EL, Talib LL, Gattaz WF, Forlenza OV: Inhibition of phospholipase A2 increases tau phosphorylation at Ser214 in embryonic rat hippocampal neurons. Prostaglandins Leukot Essent Fatty Acids 2010, 82:57-60.

83. Kuo YM, Emmerling MR, Lampert HC, Hempelman SR, Kokjohn TA: High levels of circulating Abeta42 are sequestered by plasma proteins in Alzheimer's disease. Biochem Biophys Res Commun 1999, 257:787-91.

84. Teunissen CE, de Vente J, Steinbusch HW, De Bruijn C: Biochemical markers related to Alzheimer's dementia in serum and cerebrospinal fluid. Neurobiol Aging 2002, 23(4):485-508.

85. Tan ZS, Beiser AS, Vasan RS, Roubenoff R, Dinarello CA, Harris TB, et al: Inflammatory markers and the risk of Alzheimer disease: the Framingham Study. Neurology 2007, 68:1902-8.

86. Teunissen CE, Scheltens P: Use of proteomic approaches to identify disease biomarkers. Lancet Neurol 2007, 6(12):1036-7.

87. Evans RM, Hui S, Perkins A, Lahiri DK, Poirier J, Farlow MR: Cholesterol and APOE genotype interact to influence Alzheimer disease progression. Neurology 2004, 62:1869-71.

88. Anstey KJ, Lipnicki DM, Low LF: Cholesterol as a risk factor for dementia and cognitive decline: a systematic review of prospective studies with meta-analysis. Am J Geriatr Psychiatry 2008, 16:343-54.

89. Hochstrasser T, Weiss E, Marksteiner J, Humpel C: Soluble cell adhesion molecules in monocytes of Alzheimer's disease and mild cognitive impairment. Exp Gerontol 2010, 45:70-74.

90. Ewers M, Mielke MM, Hampel H: Blood-based biomarkers of microvascular pathology in Alzheimer's disease. Exp Gerontol 2010, 45:75-79.

91. Sun MK, Hongpaisan J, Alkon DL: Postischemic PKC activation rescues retrograde and anterograde long-term memory. Proc Natl Acad Sci USA 2009, 106:14676-80.

92. de Barry J, Liégeois CM, Janoshazi A: Protein kinase $\mathrm{C}$ as a peripheral biomarker for Alzheimer's disease. Exp Gerontol 2010, 45:64-69.

93. Isagawa T, Mukai H, Oishi K, Taniguchi T, Hasegawa H, Kawamata T, et al: Dual effects of PKNalpha and protein kinase $C$ on phosphorylation of tau protein by glycogen synthase kinase-3beta. Biochem Biophys Res Commun 2000, 273:209-12.

94. Korolainen MA, Nyman TA, Aittokallio T, Pirttilä T: An update on clinical proteomics in Alzheimer's research. J Neurochem 2010, 112:1386-414.

doi:10.1186/1742-4933-8-7

Cite this article as: Davinelli et al:: The "Alzheimer's disease signature": potential perspectives for novel biomarkers. Immunity \& Ageing 2011 8:7.

\section{Submit your next manuscript to BioMed Central and take full advantage of:}

- Convenient online submission

- Thorough peer review

- No space constraints or color figure charges

- Immediate publication on acceptance

- Inclusion in PubMed, CAS, Scopus and Google Scholar

- Research which is freely available for redistribution 